\title{
Once upon a time...
}

This year 2015 marks the 30th anniversary of a simple but relevant story for respiratory medicine in Spain. In 1985, for the first time, a small group of young chest physicians, all based in Barcelona, attended the annual congress of the American Thoracic Society (ATS) in Anaheim, California. What was special about this expedition was that these fellows were presenting their own oral and poster communications, all supported by institutional grants. More importantly, their engagement and commitment to respiratory research is not only active today, but also considered internationally of great impact. This attendance at the ATS meeting represented a major breakthrough for Spanish respiratory research and was the beginning of a series of achievements that resulted in the development of one of the most active research clusters in respiratory medicine in Europe. The fact that the European Respiratory Society (ERS) nominated in 2014 eight Spanish ERS Fellows, seven of them based in Barcelona, is the best argument in support of this statement.
Some of the fellows of the 1985 team founded in 2012 the Barcelona Research Network (BRN) (http://brn.cat/), a non-profit organization whose main mission is to favor collaborative research and innovation of excellence in respiratory health in order to improve the quality of life and well being of patients. The new journal created by the BRN, BRN Reviews (http: / / www.brnreviews.com/), is one of the products of the many activities of the BRN and is also the official journal of the BRN. This will be an online, open-access quarterly journầ with the mission to publish cutting-edge, high quality, internationally authorized reviews onn current hot topics in respiratory medicine, with a special emphasis on their translational aspects that will enlighten and foster new advances and challenges in clinical practice.

I would like to take this opportunity to thank the BRN Scientific Committee, Alvar Agustí, MD, Josep María Antó, MD, Ferran Barbé, MD, Jordi, Dorca, MD, Joan Escarrabill, MD, Joaquim Gea, MD, Eduard Monsó, MD, Vicente 
Plaza, MD, and Joan Ruiz, MD, and the team of Editorial Permanyer for making possible the birth of BRN Reviews on July $1^{\text {st }} 2015$. It will be a privilege and honor to lead this challenging new editorial venture for the coming years. This great challenge will be supported by the members of the Scientific Committee who will contribute to the journal as associate editors. This will be complemented and supported by the new Editorial Board, which includes a large list of worldwide experts in different areas of respiratory medicine, covering topics spanning from basic to translational and clinical research. I am most grateful for their willingness to serve and contribute to BRN reviews.

R. Rodríguez-Roisin, Mi

Barcelona, June 22, 2015 